\title{
INCLUSÃO DE UMA ALUNA COM DEFICIÊNCIA AUDITIVA NO CURSO DE ENFERMAGEM EM UMA UNIVERSIDADE PÚBLICA DE ALAGOAS
}

\author{
INCLUSION OF A STUDENT WITH HEARING IMPAIRMENT IN A NURSING COURSE \\ IN A PUBLIC UNIVERSITY OF ALAGOAS, BRAZILL
}

\author{
Uirassú Tupinambá Silva De Lima ${ }^{1 *}$, Antonio Carlos Silva Costa ${ }^{2 *}$ \\ 1'uirassulima@yahoo.com.br. 2acscosta@uol.com.br \\ *Faculdade de Medicina da Universidade Federal de Alagoas
}

Data de entrada do artigo: 18/07/2013

Data de aceite do artigo: 21/03/2014

\section{RESUMO}

$\mathrm{Na}$ atualidade, tem-se observado um aumento no número de pesquisas enfocando a inclusão de pessoas com deficiência nas instituições de ensino superior (IES). No entanto, nos cursos de graduação da área de saúde estas investigações ainda são restritas. Diante desta situação, o presente estudo teve como objetivo compreender o processo de inclusão de uma aluna com deficiência auditiva em uma universidade pública. A metodologia utilizada foi uma pesquisa descritiva que utilizou o estudo de caso e a análise de conteúdo. Os resultados evidenciam que a inclusão desta aluna tem ocorrido de maneira satisfatória em sua percepçáo por motivos como consciência, apoio familiar, enfrentamento, relaçóes interpessoais, atendimento especializado, resiliência e envolvimento acadêmico. Conclui-se que, a partir do depoimento da aluna, foi possível verificar que o relacionar-se com as diferenças é muito importante para a conscientização das pessoas em relação ao respeito à igualdade, à singularidade e à subjetivação de cada um, visando à extinção do preconceito.

Palavras-chave: Pessoas com deficiência; perda auditiva; educação superior; enfermagem.

\section{ABSTRACT}

Nowadays one has observed an increase in the number of research studies focusing on the inclusion of people with disabilities in higher education institutions (HEIs). However, in undergraduate healthcare these investigations are still restricted. In this situation, the present study aimed to understand the process of inclusion of a student with hearing impairment in a public university. The methodology used was a descriptive research which used the case study and content analysis. The results show that the inclusion of this student has been satisfactorily on her perception for reasons such as awareness, family support, coping, interpersonal relationships, specialized care, resiliency and academic involvement. We conclude that from the testimony of the student it was possible to verify that dealing with differences is very important to people's awareness in relation to equality, individuality and subjectivity of each person, something that could diminish prejudices.

Keywords: low sodium diet; food intake; potassium chloride; hospital nutrition service. 


\section{Introdução}

Este artigo tem como objetivo compreender a trajetória e a inclusão de uma aluna com deficiência auditiva no curso de enfermagem de uma universidade pública do estado de Alagoas, a partir da perspectiva da própria aluna que, para preservar sua identidade, foi aqui denominada "Lúcia". A temática merece destaque na atualidade, já que tem sido muito abordada no ensino básico, mas com pouca abrangência no contexto universitário, em especial nos cursos de graduação em saúde. No entanto, é crescente o número de alunos com deficiência que ingressam neste nível de ensino em busca de educação profissional e oportunidades iguais aos demais alunos náo declarados deficientes.

O presente caso constitui parte da dissertação de mestrado intitulada "Inclusão do aluno com deficiência no ensino superior em saúde nas universidades públicas do estado de Alagoas" do Programa de Pós-Graduação em Ensino em Saúde da Faculdade de Medicina da Universidade Federal de Alagoas, na linha de pesquisa "Currículo e Processo de Ensino-Aprendizagem na Formação em Saúde".

Alunos com deficiência são aqueles com algum tipo de alteração em pelo menos um segmento motor, sensorial, mental ou múltiplo. Para a Organização Mundial de Saúde, a deficiência é toda perda ou anormalidade de uma ou mais estruturas do corpo, ou de sua fisiologia, inclusive as mentais ${ }^{1}$. Estima-se que 24,6 milhões de pessoas, ou seja, $14,4 \%$ da população total apresentam algum tipo de deficiência, como dificuldade de ouvir, locomover-se ou, ainda, deficiência física ou intelectual ${ }^{2}$.

A inclusão no ensino superior desse tipo de alunado tem desafiado e provocado mudanças dentro e fora dos muros das instituiçóes de ensino superior (IES), tanto em instituições públicas quanto nas privadas. Por muito tempo, estes alunos foram considerados indivíduos à margem dos grupos sociais, mas, à medida que os direitos do homem à igualdade e à cidadania tornaram-se motivo de preocupação, algumas mudanças na história começaram a ocorrer. A Educação Especial no Brasil, por exemplo, traz marcas de marginalização e assistência social. Uma breve retrospectiva da trajetória do atendimento educacional oferecido a esse grupo no país mostra que é marcado por rótulos e classificaçôes que fortalecem sempre a baixa expectativa dele, enfatizando muito mais suas limitaçóes do que suas potencialidades ${ }^{3}$.

Essa inclusão implica não apenas no acesso das pessoas com deficiência aos espaços de ensino das IES, como também terem as suas necessidades atendidas, de maneira que consigam permanecer na instituição e ter uma trajetória de aprendizado de sucesso. A exclusão tem ocorrido pelas atitudes sociais negativas como, por exemplo, o estigma social que afastava e ainda afasta em parte essas pessoas do ambiente universitário. Segundo Goffman (1998) concepção social sobre atributos diferentes em relação ao que é considerado padrão, como uma marca que determina alguns sujeitos como inferiores aos demais. É o modo como a sociedade vê, concebe e lida com a diferença”.

Cada vez mais é maior o número de alunos com necessidades especiais (devido a uma deficiência) que almejam e chegam ao ensino superior, inclusive em cursos da área de saúde como medicina, enfermagem, odontologia, fisioterapia, entre outros, algo que antes parecia impossível para estes alunos. Cursos que, além da dimensão teórica, são marcados pela dimensão do domínio das habilidades técnicas, que podem parecer, segundo a visão docente e social, incompatíveis com algumas condiçôes deste alunado ${ }^{5,6}$.

Deve-se destacar ainda que a inclusão escolar conquistada na educação infantil e na educação básica não deve sofrer um processo de interrupção quando estes alunos chegam à fase de ingresso no ensino superior, para que o discurso inclusivo não se torne uma falácia.

A deficiência auditiva abordada neste caso ocorre quando alguma das estruturas da orelha apresenta uma alteração, ocasionando uma diminuição da capacidade de perceber o som. Na maioria das vezes, a pessoa com deficiência auditiva se comunica pela fala e apresenta uma perda auditiva de grau leve ou moderado, enquanto que a surdez é a incapacidade completa em perceber o som. O surdo comunica-se por meio de linguagem de sinais e apresenta uma perda auditiva de grau severo ou profundo ${ }^{1}$.

Para o Decreto no 5.296/04, a deficiência auditiva é "a perda bilateral, parcial ou total, de quarenta e um decibéis $(\mathrm{dB})$ ou mais, comprovada por audiograma nas frequências de 500 hertz e 2.000 hertz". No Brasil, existem cerca de 5,7 milhões de pessoas com deficiência auditiva, ou seja, $2 \%$ da população apresentam uma perda auditiva. Neste caso, o termo deficiência auditiva incluía deficiência auditiva, perda parcial, e a surdez, perda severa ou profunda ${ }^{7}$.

Tanto a deficiência auditiva quanto a surdez apresentam características bem definidas, ambas são constantemente apontadas como responsáveis por limitação no desenvolvimento global com reflexos negativos nas relações sociais, psicológicas e interacionais. Sendo por este motivo fundamental a estimulação permanente de outros coadjuvantes sensoriais que desmobilizem esse quadro $^{1,8}$.

Quanto mais precocemente for diagnosticada a deficiência auditiva ou a surdez, maiores serão as chances de sucesso na reabilitaçáo, em especial quando há parceria de aparelhos de amplificação sonora individual (AASI) e a participação da família, dos educadores, da sociedade, 
de profissionais da saúde e da terapia fonoaudiológica. Por outro lado, o diagnóstico tardio causa dificuldade de desenvolvimento, em relação à linguagem ou nos níveis social, psíquico e cognitivo ${ }^{1,8}$.

Em relação ao período de aquisição, a deficiência auditiva ou a surdez podem ser congênitas, quando a pessoa já nasceu surda e neste caso a surdez é pré-lingual, ou seja, estava presente antes da aquisição da linguagem; ou adquirida quando a pessoa nasce ouvindo e perde sua audiçấo no decorrer da idade, de maneira aguda ou crônica - neste caso a surdez é pré-lingual ou pós-lingual, dependendo da perda ter sido antes ou depois da aquisiçấo da linguagem ${ }^{1,9}$. A deficiência auditiva ou a surdez podem ser pré-natais, perinatais ou pós-natais. Nas pré-natais são desencadeadas por fatores genéticos, hereditários, por doenças adquiridas pela mãe na gestação e por exposição materna a drogas ototóxicas. Nas perinatais são causadas por anoxia, fórceps, parto rápido ou demorado demais, e nas pós-natais são provocadas por meningite, caxumba, sarampo, drogas ototóxicas, idade avançada, traumas, otites e ruídos de repetição.

Uma pessoa só pode ser considerada surda quando sua audição não é funcional mesmo com o uso de próteses ou aparelhos auditivos. Por outro lado, os deficientes auditivos são aqueles que têm sua audiçáo dificultada e que podem se beneficiar com o uso de tais próteses ou aparelhos auditivos, minimizando ou até mesmo solucionando esse déficit ${ }^{1,8,9}$.

A medida mais importante para prevenção da deficiência auditiva é a vacinação contra a rubéola em mulheres em idade fértil, pois cerca de $70 \%$ dos casos de deficiência auditiva são atribuídos à aquisição dessa doença por mães no primeiro trimestre da gravidez, período no qual estáo sendo formados os olhos, as orelhas e o sistema cardíaco. Nessa fase, pode ocorrer a síndrome da rubéola congênita (SRC), que se associa, na maioria das vezes, à catarata congênita, glaucoma, retinopatia pigmentar, surdez e sopro no coraçãoo ${ }^{1,8,9}$.

A inclusão do deficiente auditivo nas salas de aula do ensino regular, em todos os seus níveis, é uma temática em evidência no contexto da educação inclusiva e uma consequência histórica do diagnóstico precoce e da estimulação que, ao longo da vida, foram oferecidos a estes alunos. Muitos estudos desenvolvidos nos últimos anos no Brasil e no exterior indicam que uma parcela significativa desses alunos, que passaram por vários anos de escolarização, desenvolvem competências e habilidades acadêmicas muito aquém do desempenho de alunos ouvintes, com capacidades cognitivas iniciais semelhan$\operatorname{tes}^{11,12,13}$. A educação inclusiva no ensino superior deve ser entendida como um movimento que não tem como finalidade privilegiar uma classe em detrimento da outra, mas uma prática educacional que atende a todas as pessoas para que possam aprender juntas, promovendo o desenvolvimento social e pessoal, independentemente das características que o alunado possa ter ou até mesmo adquirir, declarados deficientes ou não ${ }^{14}$.

Outro aspecto essencial que não se pode deixar de mencionar é que esse movimento está amparado no Brasil por dispositivos legais, entre eles: a Constituição Federal, de 1988, a Lei 7.853/1989, a Lei de Diretrizes e Bases da Educação Nacional (9.394/1.996), a Lei 10.098/2000, regulamentada pelo decreto 5296/2004, entre outras. Internacionalmente, apoia-se em documentos como a Declaração de Educação para Todos, de Jomtien, de 1990; a Declaração de Manágua, de 1993; a Declaração de Salamanca, de 1994; a Declaração Internacional de Montreal sobre a Inclusão, de 2001; e, mais recentemente, a Convenção Internacional sobre os Direitos da Pessoa com Deficiência, de 2006 $6^{1,13,14}$.

\section{Metodologia}

Este relato de caso constitui parte da dissertação de mestrado intitulada "Inclusão do aluno com deficiência no ensino superior em saúde nas universidades públicas do estado de Alagoas: atores, realidade e práticas" do Programa de Pós-Graduação em Ensino em Saúde da Faculdade de Medicina da Universidade Federal de Alagoas, na linha de pesquisa "Currículo e Processo de Ensino-Aprendizagem na Formação em Saúde". O projeto de pesquisa foi analisado e aprovado pelo Comitê de Ética em Pesquisa e Ensino do Centro Universitário Cesmac, sob o parecer de $\mathrm{n}^{\circ} 1442 / 12$.

A coleta de dados se deu pela aplicação de um questionário estruturado e um depoimento escrito pela aluna pesquisada, que possibilitaram a reunião das informaçóes necessárias para apresentação deste caso e suas reflexôes. Para extrair os significados do depoimento da aluna, foram utilizadas técnicas de análise de conteúdo preconizadas por Bardin (1977) ${ }^{15}$. Após os esclarecimentos sobre os objetivos do estudo e da metodologia utilizada, a aluna participante assinou o Termo de Consentimento Livre e Esclarecido (TCLE), conforme a Resolução no 196/96 do Conselho Nacional de Saúde, que regula as pesquisas com seres humanos. A própria aluna é colaboradora na redação deste artigo, que apresenta sua trajetória de vida e de inclusão no cenário da educação regular.

\section{Resultados e discussão}

O caso analisado é de uma jovem de 23 anos, alagoana, solteira, que desenvolveu deficiência auditiva logo após o nascimento; reside com os pais e irmãs - os pais possuem escolaridade de nível superior. Desde muito 
cedo procuraram recursos para a deficiência apresentada pela filha, sendo orientados para uma educação inclusiva baseada no oralismo. Assim aos 3 anos de idade já estava matriculada no maternal de uma escola para crianças ouvintes e sempre frequentou escolas particulares que atendessem da melhor maneira possível suas necessidades.

A aluna desenvolveu a deficiência auditiva profunda após o nascimento em razáo de uma ototoxidade desencadeada por sulfato de gentamicina, e desde cedo recebeu estimulação para o letramento e oralização. Não faz referência ao uso da Língua Brasileira de Sinais (Libras) ao longo de sua trajetória como deficiente auditiva, e diz que começou a utilizar seu primeiro aparelho auditivo aos 8 anos; relata ter apresentado muita dificuldade para adaptar-se ao uso do aparelho auditivo.

Ela conta que ao ingressar na escola, seu relacionamento com os colegas foi tranquilo e de colaboração, apesar de sentir desde o começo problemas com a comunicação. Sua percepção de que apresentava uma diferença em relação às outras crianças foi confirmada quando recebeu um diagnóstico médico conclusivo após um exame específico. No trecho (T) 18 de seu depoimento na categoria 5, confessa que este foi um período difícil da sua vida.

É possível pensar que Lúcia estivesse deprimida, pois segundo autores como $\mathrm{Fu}$-i et al. $(2012)^{16}$ a depressão na infância pode manifestar-se com comportamentos como agressividade, vergonha, revolta e raiva. Gonzáles e Díaz $(2007)^{9}$ por sua vez defende que o papel da palavra vai além do pensar nexos, impondo uma ordem, uma organização intrapsíquica.

A sensibilidade dos pais de Lúcia foi fundamental para a superação dos problemas enfrentados por ela e para sua inclusão social, pois procuraram intensificar as interaçóes comunicativas, entender o que acontecia com a filha e buscar ajuda adequada. Nos trechos 3 e 4 , da categoria 2, a fala da aluna aborda a importância do apoio familiar em sua busca por experiências significativas a partir de sua inclusão.

Após superar as dificuldades do processo identificatório, Lúcia conseguiu aceitar sua condição, sem ter introjetado uma imagem negativa. E define bem sua posiçáo, no trecho 21 da categoria 6 , quando afirma em seu depoimento que aprendeu a conviver e a aceitar bem sua deficiência como estratégia facilitadora de superação.Assim conseguiu concluir o ensino médio em 2007 em escola privada e, logo em seguida, decidiu seguir o curso de enfermagem como opção profissional. Seu acesso ao curso deu-se por meio de vestibular tradicional e sem cota, não sendo solicitada por ela na oportunidade a presença de um intérprete ou nenhum outro tipo de atendimento pedagógico especializado. Nunca trancou matrícula no curso de enfermagem. Como atividades complementares estuda Inglês e Alemão.
Da análise do depoimento dessa aluna com deficiência auditiva e, mediante a exploração destas informaçôes, emergiram seis categorias:

\section{Categoria 1: Descoberta, identidade e consciência da deficiência auditiva}

Para Glat e Duque $(2003)^{17}$, por mais harmônica que seja uma família, a crise desencadeada pela descoberta da deficiência é inevitável, pois implica na pessoa com deficiência e sua família viver situações críticas e sentimentos difíceis de enfrentar. Silva, Zanolli e Pereira $(2008)^{18}$, a partir de um estudo em que abordavam relatos de mães diante do diagnóstico de surdez, reforçam que independentemente da concepção que essa família tenha desse agravo, esse acontecimento é sempre desestruturador.

T1: A descoberta da "minha deficiência auditiva" foi quando eu estava no jardim da infância, porque meus coleguinhas de classe pediam para a minha professora falar um pouco mais alto para que eu pudesse ouvir. Cheguei a repetir o Jardim II, porque tinha dificuldade na leitura e escrita. Minha professora me incentivou a ler gibis, revistas e demais materiais escritos, para melhorar o meu potencial cognitivo.

T2: Nas escolas sempre tive meu lugar "marcado", era sempre a primeira cadeira do meio da sala. Sempre fui hiperativa, comunicativa, fazia amizades facilmente. Mas sempre tive vergonha de dizer o "meu problema". Só meus coleguinhas de classe sabiam. Pra evitar que todos soubessem, só usava os aparelhos dentro da sala.

\section{Categoria 2: Apoio familiar na inclusão}

O papel da família é fundamental no processo de inclusão, pois cabe a ela preparar o filho para conviver fora do núcleo familiar com as diversidades e fazer um acompanhamento sistemático no desempenho do ensino-aprendizagem. A aluna aqui pesquisada, em vários trechos de seu depoimento, reconhece o apoio familiar recebido dos pais e irmãs.

T3: Minha mãe sempre notou que eu era uma pessoa "especial", demorei a falar, tinha dificuldade na fala, não respondia quando ela me chamava. As pessoas que mais me ajudaram a falar foram as minhas irmãs, elas sempre me acompanharam e sempre me corrigiam quando eu falava errado. A rotina delas era a minha.

T4: Hoje estou no meu último ano do curso de Enfermagem, com saldo negativo com todos aqueles que me apoiaram e incentivaram. Não deixando de lado 
aqueles que me apoiaram com palavras. Principalmente, meus pais, em especial, minha querida mãe, que sempre fez que eu acreditasse que sou capaz de conquistar o que desejo, minhas queridas irmãs que dedicaram e abdicaram parte de seu tempo para me auxiliar nos estudos.

O valor dado pela aluna ao apoio familiar recebido demonstra, segundo Glat e Duque $(2003)^{17}$, o significado decisivo da família no sucesso da inclusão escolar e social: colaborando, por exemplo, de maneira muito especial para o desenvolvimento desse tipo de aluno e fornecendo aos profissionais informaçóes sobre as formas de comunicação e apoio incondicional.

\section{Categoria 3: Obstáculos enfrentados}

A inserção no cenário pedagógico regular é um desafio constante para o aluno com deficiência auditiva, principalmente porque, em geral, o professor não está preparado para receber esse tipo de aluno - muitos deles admitem que precisam de ajuda e outros náo se dispóem a ter uma qualificação para lidar com uma situaçáo nova. Seguem alguns depoimentos da aluna que demonstra seus sentimentos em relação a alguns obstáculos vivenciados em sua inclusão escolar:

T5: Sempre frequentei escolas normais, por sinal, as melhores escolas particulares de minha cidade. Tive dificuldade de adaptação com o professor; por esse motivo, minha mãe evitava me mudar de escola. Para eu melhor me adaptar com o professor era todo um processo; tenho de me acostumar a sua gesticulação ao falar, som da voz etc. Minha vida toda estudei em 4 escolas: FFFF (atualmente, GGGG), AAAA, Colégio MMMM (onde estudei mais tempo, 8 anos, da $3^{\text {a }}$ série do fundamental ao $2^{\circ}$ ano do ensino médio) e o Colégio CCCC, onde concluí meu Ensino médio. O grande destaque do Colégio CCCC era que os professores utilizavam microfones e isso me ajudava bastante.

T6: Na faculdade tive muitas dificuldades. E não recebi suporte como "aluna portadora de deficiência auditiva", não obtive ajuda de nenhum tipo de equipamento/instrumento, a não ser dos meus aparelhos, para melhor ouvir. Uma das ajudas que me fez superar as minhas dificuldades foi a ajuda de meus colegas de turmas, que hoje vejo que são grandes amigos e serei eternamente grata.

T7: Escutar o professor quando ele se encontra de costas durante a aula, isso dificulta a leitura labial.

T8: Às vezes, quando o professor náo disponibiliza as aulas, fica difícil acompanhar a aula e escrever ao mesmo tempo, pois professores "não respeitam" o tempo que levo para assimilar o assunto e depois escrever.

Outro aspecto do qual a aluna se ressente é a ausência de uma atenção pedagógica especializada, principalmente nas aulas práticas. Em geral, nas escolas de enfermagem não existe preparo pedagógico que qualifique o enfermeiro para a docência. Com frequência, o professor é contratado pela habilidade técnica, pelo currículo, e às vezes pelo histórico como pesquisador em saúde, como se a didática resultasse implicitamente da soma ou de um destes fatores ${ }^{19}$.

T9: Tenho dificuldades em realizar algumas práticas que exige (sic) o uso da audição para ausculta pulmonar com uso de estetoscópio; se uso em demasia acaba incomodando e fico com dores no ouvido.

T10: Os professores em prática não dão atenção individualizada; por exemplo, quando na prática o ambiente exige o uso de máscara, fica difícil e afeta a minha comunicação com o professor.

T11: Na sala de aula há vários fatores que dificultam a interação em sala, como, por exemplo, não usam microfones; há muitos alunos em sala e fica difícil entender os professores ou até mesmo interagir melhor no processo de aprendizagem.

T12: Os professores às vezes costumam fazer "videoaulas"; foram poucas as vezes que trouxeram com legendas. Então, fica impossível assistir (sic) vídeos que não estejam com legendas.

T13: Em relação às aulas: são corridas com um pequeno tempo de intervalo, ou seja, é dada a aula em 3 horas corridas, sem interrupção, o que de fato "cansa" de tanto forçar para ouvir e poder interagir.

T14: No início do curso, utilizei alguns artifícios: gravava aulas de anatomia no meu mp3 e depois transcrevia com a ajuda da minha irmã mais nova, CCCC. Fui um pouco doloroso, pois eu teria de ouvir no volume máximo pra poder ouvir bem. E houve dias que forcei demais a audição e tive uma otite. Outra dificuldade durante o curso de Enfermagem (até os dias de hoje) foi na distinção de sons na ausculta cardíaca, como também na ausculta pulmonar, pois ao usar estetoscópio é preciso que eu retire os aparelhos.

T15: (...) Ganhei bastantes aparelhos [auditivos] modernos de última geração, mas o fato de ter de usar um aparelho bastante visível sempre me incomodou.

Manente, Rodrigues e Palamin (2007) ${ }^{10}$ realizaram uma pesquisa com 69 deficientes auditivos sobre sua 
inclusão no ensino superior. Os resultados demonstraram que estes alunos apontam a ajuda dos colegas e da família como as principais maneiras de superação dos obstáculos vividos na academia. $\mathrm{Na}$ fala da aluna aqui pesquisada, destacada a seguir, é possível evidenciar essa mesma perspectiva. Vale ressaltar que em outros trechos, ao longo das demais categorias de estudo, é possível constar o reconhecimento que ela dá às pessoas significativas que, de alguma maneira, têm colaborado para sua inclusão.

T16: Uma das ajudas que me fez superar as minhas dificuldades, foi à (sic) ajuda de meus colegas de turma, que hoje vejo que são grandes amigos e serei eternamente grata.

Para Freire $(2005)^{20}$, a transposição de obstáculos do alunado na condição de emancipá-los ao estimular sua criticidade seria o caminho de um processo de inclusão, na possibilidade de um novo conhecimento, o coletivo.

\section{Categoria 4: Relacionamento Interpessoal}

Antes da entrada no curso de enfermagem, essa aluna já valorizava os relacionamentos interpessoais, aqui expressos em relação aos seus familiares e colegas, destacando em sua fala sempre o companheirismo destas relaçôes. As relaçôes interpessoais, como coadjuvante facilitador em seu processo de inclusão, são mencionadas em diversos momentos de seu depoimento e, por esta razão, foram exploradas em várias categorias de análise que fazem parte desse estudo.

T16: Uma das ajudas que me fez superar as minhas dificuldades foi a ajuda de meus colegas de turma, que hoje vejo que são grandes amigos e serei eternamente grata.

T17: Tive grandes amigas no Colégio MMMM, fui destaque como aluna de química e formei um grupo de estudo para ajudar minhas amigas que tinham dificuldades com essa disciplina.

T18: Apoio materno, apoio de colegas e ajuda na realização de algumas tarefas e principalmente apoio financeiro de meus pais.

O estabelecimento de relações empáticas e genuínas com pessoas significativas - no caso em discussão, professores e colegas - aumenta a capacidade de autocompreensão e autoestima, sentimentos que podem estimular a criatividade e o crescimento pessoal, aspectos importantes que devem ser considerados no desempenho do profissional da área de saúde. Karagiannis, Stainback e Stainback $(2006)^{21}$ completam que a dinâmica entre estes sentimentos são fundamentais para que ocorra o processo de inclusão educacional dos alunos com deficiência.

\section{Categoria 5: Atendimento Especializado}

$\mathrm{O}$ atendimento especializado interprofissional é determinante para o desenvolvimento sensorial e para o processo de integração e inclusão da pessoa com deficiência auditiva na sociedade de ouvintes e não ouvintes, em todos os graus de severidade da deficiência ${ }^{1,8}$.

A preocupação com o atendimento especializado para o acolhimento e para prevenção das dificuldades mais comuns da audiocomunicação que se instala no aluno com deficiência auditiva parece ser um conteúdo muito significativo para esta aluna e seus familiares, aspecto facilmente identificável nos trechos T19, T20 e T21, que seguem nesta categoria.

A adaptação da prótese auditiva, parte do atendimento especializado, é uma das condiçóes fundamentais para que o deficiente auditivo desenvolva todo seu potencial, o que ocorrerá apenas quando ele utilizar plenamente o instrumento, isto é, em todas as horas do dia. Este processo dependerá da participação e do apoio da família. Desse modo, a utilização do aparelho estará diretamente relacionada à atitude e à educação do deficiente e de seus familiares mais próximos. Muitos fatores estão relacionados à rejeição da prótese, e um dos principais é a não aceitação por parte da própria família e a vergonha de utilizá-lo. O depoimento a seguir ilustra bem esse conflito na vida da aluna aqui pesquisada ${ }^{8}$.

T19: Com 7 anos, fui a Recife fazer o Bera (Exame do Potencial Evocado Auditivo do Tronco Encefálico) e constatou-se perda profunda. Foi um impacto muito grande para mim e para minha mãe, pois eu não aceitei bem o fato de ter de usar aparelhos em ambos os ouvidos por vergonha e por medo de ser rejeitada pelos coleguinhas. Comecei a usar meu primeiro aparelho com 8 anos de idade. Pra mim, era totalmente diferente usar aparelhos auditivos do que usar óculos. Óculos eram comuns, a maioria das pessoas usava, e aparelhos auditivos? Nunca tinha visto alguém ajudar e muito menos nenhum coleguinha meu da sala usava. Passei a usar com mais frequência na minha adolescência, por incentivos de familiares e amigos.

T20: Tive acompanhamento de uma "fono" chamada Suelly, que me ajudou bastante a melhorar minha dicção (mas ainda hoje tenho dificuldade de articular algumas palavras) e a fazer leitura labial. O engraçado é que consigo fazer uma boa leitura labial que todos dizem que "só escuta quando quer" ou "quando falam mal de mim". Com essa "fono", consegui que meu acompanhamento 
fosse feito em Bauru/SP, no Centro Educacional do Deficiente Auditivo (Cedau), onde havia os melhores profissionais na área, pois aqui não havia muitos.

T21: Em 2000, tive a oportunidade de ir pra Köln [Colônia, Alemanha], minha primeira viagem internacional, para me consultar com o "otorrino" de lá [Dr. Thomas Langhammer]. Um médico muito competente, amigo de meus familiares que lá residem, muito cobiçado e um excelente profissional. Diagnosticou perdas em ambos os ouvidos, mas um com perda profunda (OD) e o outro, com perda severa (OE). Ganhei de presente dois aparelhos modernos, muito pequenos (intra-aurais). Daí não pude dar como desculpa por não usar o aparelho "por ser grande demais" ou "todos irão notar”.

O propósito norteador desse atendimento é desenvolver a competência lingüística e textual, para que este alunado seja capaz de ler e escrever em língua portuguesa, e assim exercer sua cidadania e seus direitos sociais, entre eles, o de prosseguir seus estudos em salas de aula regulares.

\section{Categoria 6: Resiliência e pertencimento}

Em vários momentos da fala da aluna, sobretudo nos trechos abaixo (T22 e T23), verifica-se seu potencial em se adaptar com facilidade às diversidades, às alteraçôes ou aos infortúnios de sua trajetória de vida. Essa expressão comportamental, chamada de resiliência, segundo Barbosa $(2006)^{22}$, consiste na habilidade de uma pessoa de persistir nos momentos difíceis, mantendo sua esperança e saúde mental. Garmezy (1991) ${ }^{23}$ por sua vez defende que essa resiliência é marcada por sentimentos positivos de pertencimento e de maturidade da pessoa, a partir do embate e do sofrimento com sua realidade. Sendo assim, a pessoa resiliente se fortalece na luta e na busca da superação.

T22: Acredito que quando se almeja algo de verdade, devem-se superar os obstáculos. Deficiência não é dificuldade, nem muito menos empecilho. Deve-se primeiramente SE ACEITAR e ser a melhor amiga da deficiência, pois ela nunca vai te deixar e, se você a tornar sua inimiga, ela será uma barreira para a realização dos seus sonhos.

T23: (...) Estou satisfeita com meu curso e sei que darei conta das responsabilidades exigidas em minha profissão, pois minha dificuldade de ouvir já era uma realidade minha desde o primeiro momento que pensei em ser enfermeira. E para isso vou dar o meu melhor.
São características da resiliência, apontadas pela literatura, encontradas nesta aluna: sociabilidade, criatividade, criticidade, senso de autonomia e enfrentamento. A resiliência e o pertencimento são construtos psicológicos que colaboram com o desenvolvimento humano a partir do embate e da superação dos conflitos. Essa habilidade de superar adversidades não significa que a pessoa não saia ilesa de suas crises e conflitos, mas evidencia sua capacidade positiva de lidar com sentimentos existenciais de discriminação, depressão, ansiedade, medo, angústia e agressividade ${ }^{10,22,23}$.

\section{Conclusão}

Este estudo conseguiu mostrar as características da inclusão escolar de uma aluna com deficiência auditiva a partir de trechos de sua trajetória de vida. Dessa maneira, ao socializar essa história particular, a possibilidade de inclusão de pessoas com deficiência ganha vida e plasticidade, deixando de ser um sonho e passa a ser encarada como uma possível realidade cada vez mais próxima de todos.

Foi possível constatar que o papel da família, dando apoio incondicional, é fundamental para que o acesso e a permanência deste alunado ocorra da maneira mais satisfatória possível - a partir da formação de constructos como autoconfiança e autoimagem, que são estruturas de base para que se consolide a integração e inclusão social.

Outro aspecto também observado na fala da aluna é o destaque que dá às relações interpessoais, tanto familiares como entre os colegas de sala de aula, tendo professores e alunos como coadjuvantes para seu crescimento pessoal e acadêmico. Dessa forma, a partir do depoimento da aluna foi possível verificar que o relacionar-se com as diferenças é muito importante para a conscientização das pessoas em relação ao respeito à igualdade, à singularidade e à subjetivação de cada um, visando à extinção do preconceito. Esse respeito facilita a elaboração do luto por parte das pessoas com deficiência e seus familiares em relação ao corpo narcísico, aceitando a si próprio e suas limitaçóes.

Fica a lição de que a inclusão do aluno com deficiência auditiva deve acontecer desde a educação infantil até o ensino superior, com o acesso, desde cedo, a todos os recursos pedagógicos e de assistência, para que consiga minimizar ou superar as barreiras que podem impedir seu processo de socialização e de aprendizagem.

\section{Conflito de interesse}

Os autores declaram não haver nenhum conflito de interesse. 


\section{Referências}

1. Honora M, Frizanco M. Esclarecendo as deficiências: aspectos teóricos e práticos para contribuir com uma sociedade inclusiva. São Paulo: Ciranda Cultural; 2008.

2. Instituto Brasileiro de Geografia e Estatística. Censo 2000. Rio de Janeiro; 2000. Disponível em: <http://www.ibge. gov.br>.

3. Andrade MAS de, Pacheco ML, Farias SSP. Pessoas com deficiência rumo ao processo de inclusão na educação superior. Revista Digital de Pesquisa Conquer. Barreira (BA): Faculdade São Francisco de Barreiras; 2006. Disponível em: <http://www.edu.br/revista/index.php/view/27/9>

4. Goffman E. Estigma: notas sobre a identidade deteriorada. 4ed. Rio de Janeiro: LTR; 1998.

5. Censo da Educação Superior. Brasília: MEC/INEP 2006. Disponível em: <http://dados.gov.br/dataset/ microdados-do-censo-da-educacao-superior/resource/ d534bd91-99d9-45c6-9529-1045f1884d2d>

6. Censo da Educação Superior. Brasília: MEC/INEP, 2007. Disponível em: <http://download.inep.gov.br/download/ superior/censo/2007/Resumo_tecnico_2007.pdf>

7. BRASIL. Ministério de Estado da Educaçáo. Portaria no 3.284 , de 7 de novembro de 2003. Dispóe sobre requisitos de acessibilidade de pessoas portadoras de deficiências, para instruir os processos de autorização e de reconhecimento dos recursos e credenciamento de instituiçóes. 2003. Disponível em: <http://www.mec.gov.br>

8. Almeida K, Iörio CMM. Próteses Auditivas: Fundamentos Teóricos e Aplicaçóes Clínicas. São Paulo: Lovise; 1996.

9. González E, Díaz JM. Deficiência auditiva: avaliação e intervenção. In: González, Eugenio. Necessidades educacionais especiais. Tradução: Dais Vaz de Moraes. Porto Alegre: Artmed; 2007.

10. Manente MV, Rodrigues OMPR, Palamin MEG. Deficientes auditivos e escolaridade: fatores diferenciais que possibilitam o acesso ao ensino superior. Revista Brasileira de Educação Especial. 2007 jan-abr; 13(1):27-42.

11. Chahini THC, Silva SMM. Educação Superior: os desafios do acesso e da permanência de alunos com deficiência auditiva em São Luís do Maranhão. Anais do XVIII Encontro de Pesquisa Educacional do Norte Nordeste/EPENN. Maceió: Universidade Federal de Alagoas; 2007.

12. Ferreira SL. Ingresso, permanência e competência: uma realidade possível para universitários com necessidades educacionais especiais. Rev Bras Ed Esp. 2007; 13(1):43-60.

13. Fumes NLF, Calheiros DS. A inclusão de alunos com deficiência na educação superior: a experiência das instituiçóes privadas de ensino de Maceió/AL. In: IV Seminário sobre educação e inclusão social de pessoas com necessidades especiais; 2010.

14. Moreira LC, Correia G. Transformando nós em laços: Percalços e vicissitudes da inclusão na Universidade Federal do Paraná. In: 16º Cole. Campinas: Unicamp. 2007; 1:1-10.

15. Bardin L. Análise de Conteúdo. Lisboa: Ediçóes 70; 1977.

16. Fu-i L, Boarati MA, Maia APF. Transtornos Afetivos na Infância e na Adolescência: Diagnóstico e Tratamento. Porto Alegre: Artmed; 2012.

17. Glat R, Duque MA. Convivendo com filhos especiais: o olhar paterno. Rio de Janeiro: Sette Lettras; 2003.

18. Silva ABP, Zanolli ML, Pereira MCC. Surdez: relato de mães frente ao diagnóstico. Revista Estudos de Psicologia, São Paulo; 2008; 13(2):175-183.

19. Batista NA. O professor de medicina em sala: vivenciando uma prática. In: Batista N A, Silva S H B. O professor de medicina. São Paulo: Loyola; 1998:111-124.

20. Freire P. Pedagogia do oprimido. 46 ed. Rio de Janeiro: Paz e Terra; 2005.

21. Karagiannis A, Stainback S, Stainback W. Fundamentos do Ensino Inclusivo. In: Stainback $S$, Stainback W. Inclusão: um guia para educadores. Porto Alegre: Artes Médicas Sul; 2006.

22. Garmezy N. Resiliensy and vulnerability to adverse developmental outcomes associated with poverty. American Behavioral Scientist. 1991; 34:416-430.

23. Barbosa GS. Resiliência em professores do ensino fundamental de $5^{\mathrm{a}}$ a $8^{\mathrm{a}}$ Série: Validaçáo e aplicaçáo do questionário do índice de Resiliência: Adultos Reivich-Shattél Barbosa. Tese (Doutorado em Psicologia Clínica). São Paulo: Pontifícia Universidade Católica; 2006. 